\title{
IFN- $\gamma$ down-regulates Hsp27 and enhances hyperthermia-induced tumor cell death in vitro and tumor suppression in vivo
}

\author{
MARIKO OBA, SHUICHIRO YANO, TSUYOSHI SHUTO, MARY ANN SUICO, \\ AYAKA EGUMA and HIROFUMI KAI \\ Department of Molecular Medicine, Graduate School of Pharmaceutical Sciences, Global COE \\ 'Cell Fate Regulation Research and Education Unit', Kumamoto University, Kumamoto 862-0973, Japan
}

Received December 28, 2007; Accepted February 26, 2008

\begin{abstract}
Hyperthermia is used as one of the treatment modalities for various types of cancer, but the acquisition of thermotolerance in cancer cells, through the induction of heat shock proteins (Hsps), renders hyperthermia less effective. Among the Hsp family members, Hsp27 is frequently associated with thermotolerance and chemoresistance. Thus, down-regulation of Hsp27 expression during hyperthermic or chemotherapeutic applications is a promising approach to efficient tumor treatment. In the present study, we found that the cytokine interferon-gamma (IFN- $\gamma$ ) suppresses the basal, the heat shock-induced and the cisplatin-induced expression of Hsp27 in HSC-2 (oral squamous carcinoma) and A549 (lung cancer) cells but not in 16HBE14o- (normal bronchial epithelial cells). Neither IFN- $\alpha$ nor IFN- $\beta$ affected Hsp27 expression, suggesting the specificity of IFN- $\gamma$. We also demonstrate here that IFN- $\gamma$ suppresses Hsp27 basal transcription and promoter activity, and this is mediated specifically through one of the two Sp1 sites in the proximal region of the Hsp27 promoter. More importantly, pretreatment of cells with IFN- $\gamma$ enhanced the induction of cell death by hyperthermia and cisplatin treatments in the tumor cell lines, HSC-2 and A549, but has no effect in $16 \mathrm{HBE} 14 \mathrm{o}-$, indicating a tumor cell-specific effect of IFN- $\gamma$. Furthermore, the combination treatment of hyperthermia and IFN- $\gamma$ suppressed tumor growth in vivo more effectively than hyperthermia treatment alone. Together, our findings propose that IFN- $\gamma$ could be a useful potentiator of hyperthermia and cisplatin in cancer therapy.
\end{abstract}

Correspondence to: Dr Hirofumi Kai, Department of Molecular Medicine, Faculty of Medical and Pharmaceutical Sciences, Kumamoto University, 5-1 Oe-honmachi, Kumamoto 862-0973, Japan

E-mail: hirokai@gpo.kumamoto-u.ac.jp

Key words: IFN- $\gamma$, Hsp27, hyperthermia, heat shock, tumor cells, $\mathrm{Sp} 1$

\section{Introduction}

Hyperthermia has been reported to produce regression of tumors, has few side effects and is applicable to a wide range of cancer types (1-3). On the other hand, the effect of hyperthermia is weak when used alone due to the thermotolerance of cancer cells induced by heat shock proteins (Hsps) (4-6). Hsps are cytoplasmic chaperones, and are classified into subfamilies according to their molecular size. Among them are Hsp27 and Hsp72, which are known to possess cytoprotective function and are induced by anticancer stimuli such as hyperthermia and chemotherapeutic drugs $(7,8)$. Because Hsp27 and Hsp72 are associated with the acquisition of resistance to cytotoxic stimuli, especially in cancer cells, down-regulation of Hsps during hyperthermic or chemotherapeutic applications is a promising approach to efficient tumor treatment (9).

IFN- $\gamma$ is a type of cytokine, which has anti-proliferating and immuno-modulatory effects, and is used for treatment of several types of cancer $(10,11)$. In addition, there are reports that IFN- $\gamma$ enhances the effect of some chemotherapeutics (12-14). It was previously shown that mild hyperthermia enhances the anti-proliferative effect of IFN- $\gamma$ together with IFN- $\alpha$ or $-\beta(15,16)$. But these in vitro studies could not clarify the mechanism of the effects of hyperthermia and interferon combinatorial treatment. Recently, Yonekura et al showed that IFN- $\gamma$ down-regulates Hsp27 expression and enhances cisplatin-induced cell death in oral squamous carcinoma cells, and Saile et al showed that IFN- $\gamma$ suppressed Hsp72 expression in hepatic stellate cells $(17,18)$. From these reports, we hypothesized that IFN- $\gamma$ can enhance the antitumor effect of hyperthermia and chemotherapeutics.

In the present study, we demonstrated that hyperthermia together with IFN- $\gamma$ treatment significantly suppressed tumor growth in vivo and increased tumor cell death in vitro. We also confirmed that IFN- $\gamma$ down-regulated Hsp27 and Hsp72 expression in tumor cells subjected to heat shock or treated with cisplatin. More interestingly, we demonstrated here that these effects are specific for cancer cell lines. Furthermore, we showed that the $\mathrm{Sp} 1$ binding site in the promoter of Hsp27 is important for IFN- $\gamma$-induced Hsp27 suppression. Our results suggest that IFN- $\gamma$ in combination with hyperthermia or cisplatin could be a useful method for cancer therapy. 
Table I. Sequences of nucleotides used as primer for PCR amplification.

\begin{tabular}{ll}
\hline 5' Hsp27prom (-1090) & 5'-CGCGTGTGCAGACGTGTCTGTCC-3' \\
5' Hsp27prom (-175) & 5'-TAAGATCTGATGAGGGCTGAACCCTC-3' \\
5' Hsp27prom (-93) & 5'-CGAGATCTCGGGTCATTGCCATTAAT-3' \\
3' Hsp27 promoter & 5'-GAAGAACCGGCGCCATCGACGTACC-3' \\
Hsp27prom_mt1_sense & 5'-GGAGTGCATGGGGAGGAGCTCCCCTCAAACGGGTC-3' \\
Hsp27prom_mt2_sense & 5'-GCTGAACCCTCTTCGCGTCGACCACGGCCCCTGAACGC-3' \\
5' Hsp27_Q-PCR & 5'-CAGTCTCATCGGATTTTGCAGC-3' \\
3' Hsp27_Q-PCR & 5'-TGTCCCTGGATGTCAACCACTT-3' \\
5' GAPDH & 5'-GGCAGTGATGGCATGGACTG-3' \\
3' GAPDH & 5'-CGGGAAGCTTGTGATCAATGG-3'
\end{tabular}

\section{Materials and methods}

Reagents. Recombinant human IFN- $\gamma$ was purchased from R\&D System (Minneapolis, MN). Clinical grade IFN- $\alpha$ (Advaferon) was kindly provided by Yamanouchi Pharmaceutical (Tokyo, Japan) and IFN- $\beta$ was kindly provided by TORAY Industries (Chiba, Japan). These reagents were dissolved in phosphate buffered saline [PBS(-)] with $0.1 \%$ bovine serum albumin. Cisplatin [cis-platinum (II) diamine dichloride], which was kindly provided by Nippon Kayaku (Tokyo, Japan), was dissolved in saline. For the mice experiments, recombinant human IFN- $\gamma$ (Immunomax- $\gamma$ ) was purchased from Shionogi \& Co., Ltd (Osaka, Japan).

Cell culture and treatment. The lung adenocarcinoma cell line, A549, was maintained in Dulbecco's modified Eagle's medium (DMEM), and human cervix carcinoma cell line, HeLa, was maintained in minimum essential medium (MEM). Human oral squamous cell carcinoma (HSC-2), which was kindly provided by A. Uehara (Tohoku, Japan), was maintained in RPMI-1640. Normal human bronchial epithelial cell line, 16HBE14o-, was maintained in MEM and grown on culture dishes coated with human fibronectin. All media were supplemented with $10 \%$ fetal bovine serum and antibiotics. Cells were kept at $37^{\circ} \mathrm{C}$ in a humidified $5 \% \mathrm{CO}_{2}$ and air atmosphere. Cells were treated with the indicated concentrations and times with IFN- $\alpha,-\beta$, or $-\gamma$ or with PBS containing $0.1 \%$ bovine serum albumin as control. For heat shock treatment in vitro, cells were plated in $35-\mathrm{mm}$ dishes. When cells were subconfluent, the plates were sealed and placed in Petri dishes, which were submerged in a water bath maintained at $42^{\circ} \mathrm{C}$ or $44^{\circ} \mathrm{C}$ for 2 or $1 \mathrm{~h}$, respectively. Media were changed and cells were re-incubated at $37^{\circ} \mathrm{C}$ until assay.

Western blot analysis. Western blot analysis was carried out as described elsewhere (19). Whole cell lysates were isolated from the cells using hot electrophoresis sample buffer [pre-heated at $90^{\circ} \mathrm{C} ; 0.0625 \mathrm{M}$ Tris- $\mathrm{HCl}(\mathrm{pH} \mathrm{6.8)}$, $10 \% \mathrm{v} / \mathrm{v}$ glycerol, $2 \%$ sodium dodecyl sulfate], boiled at $100^{\circ} \mathrm{C}$ for $5 \mathrm{~min}$ and added with $1 \mathrm{mM}$ PMSF. These lysates were subjected to Western blotting. Protein blots were probed with monoclonal mouse anti-Hsp27, mouse anti-Hsp72 or rat anti-Hsc73 antibodies (Stressgen Biotechnologies, San Diego, CA).

Quantitative real-time RT-PCR analysis. Quantitative realtime RT-PCR analysis of Hsp27 and GAPDH was carried out with the SYBR-Green Master Mix (Applied Biosystems) according to the manufacturer's instructions. PCR amplifications were performed using GeneAmp5700 thermal cycler (Perkin-Elmer, Wellesly, MA) with the following amplification conditions: $50^{\circ} \mathrm{C}$ for $2 \mathrm{~min}, 95^{\circ} \mathrm{C}$ for $10 \mathrm{~min}$, for 40 cycles at $95^{\circ} \mathrm{C}$ for $15 \mathrm{sec}$ (denaturation step), at $60^{\circ} \mathrm{C}$ for $1 \mathrm{~min}$ (annealing/extension steps). The $\mathrm{Ct}$ values for each gene amplification were then normalized by subtracting the $\mathrm{Ct}$ value calculated for GAPDH. The normalized gene expression values were expressed as the relative quantity of gene-specific mRNA compared to GAPDH mRNA (fold induction). The oligonucleotide primers for Hsp27 and GAPDH are listed in Table I.

Cloning of Hsp27 genomic 5' region and construction of luciferase reporter gene plasmids. The $1.1 \mathrm{~kb}$ upstream (20) of Hsp27 gene was amplified with the primers, 5' Hsp27prom (-1090) and 3' Hsp27 promoter, and cloned into TOPO-Blunt vector (Invitrogen, Carlsbard, CA). Hsp27 promoter-luc reporter plasmid was constructed by subcloning Hsp27 promoter fragment $(-1090 /+38)$ into the BglII-HindIII sites of pGL3-Basic vector (Promega, Madison, WI). Deletion mutants of Hsp27 promoter $(-175 /+38$ and $-93 /+38)$ were constructed by PCR-based approach using the $-1090 /+38$ construct as template. The point mutant constructs were prepared using Quik change II XL site-directed mutagenesis kit (Stratagene, La Jolla, CA) according to the manufacturer's instructions. Mutant plasmids were made using the $-175 /+38$ construct as template. All the plasmids used in this study were sequenced with ABI3730XL DNA sequencer at the genomics facility of Macrogen (Seoul, South Korea). The sequences of primers used for making the constructs are shown in Table I.

Transient transfection and luciferase assay. Transient transfections of plasmid DNAs were performed with HilyMax (Dojindo, Kumamoto, Japan) according to the manufacturer's recommendations. For the promoter assays, A549 cells 
were seeded in 24-well plates and transfected with $0.3 \mu \mathrm{g}$ reporter plasmid and $5 \mathrm{ng}$ phRG-TK vector (Promega), which expresses Renilla luciferase, to normalize the luciferase reporter activity. After transfection, the cells were treated with the indicated reagents and re-incubated for another $48 \mathrm{~h}$. Mithramycin A (Sigma, St. Louis, MO) was added $12 \mathrm{~h}$ before harvesting the cells. Luciferase activity was measured using Dual Luciferase Reporter assay system (Promega) according to the manufacturer's instructions. Relative luciferase activity is plotted and represents the fold induction of experimental treatment with respect to the activity of basic vector alone. Values are shown as means $\pm \operatorname{SE}(n=3)$.

Lactate dehydrogenase ( $L D H)$ assay. After cells were treated with heat shock and cisplatin, culture media were isolated and centrifuged at $12,000 \mathrm{rpm}$ for $15 \mathrm{~min}$. Supernatants were recovered, and cell pellets were lysed by adding $1 \%$ Triton X-100 solutions for $30 \mathrm{~min}$ at $37^{\circ} \mathrm{C}$. The remaining attached cells in plates were also lysed with $1 \%$ Triton $\mathrm{X}-100$ solution. Culture media, cell pellets and lysates were subjected to LDH assay using the Cytotoxicity Detection Kit (Roche Applied Science, Indianapolis, IN) according to the manufacturer's instructions. LDH release was expressed as percentage of the LDH in the medium and pellet over the total LDH (medium, pellet and lysate). Values are the means \pm SE of 3 determinants for a representative experiment. Significance of the difference between PBS-treated and IFN- $\gamma$-treated groups was assessed with one-way ANOVA.

Treatment and tumor growth assay in mice. Six-week old female ICR nude mice (Crj:CD-1 ICR -nu/nu SPF/VAF mice; KBT Oriental, Saga, Japan) were housed in a vivarium in accordance with the guidelines of the animal facility center of Kumamoto University. The mice were maintained on food and water ad libitum. For the in vivo tumor regression assay, exponentially growing A549 cells (2x10 cells) were implanted subcutaneously into the dorsal region of each nude mouse. Four weeks after implantation, the mice were treated with IFN- $\gamma$ or saline and whole body hyperthermia once a week. IFN- $\gamma\left(1 \times 10^{5} \mathrm{IU}\right)$ or saline was subcutaneously injected $48 \mathrm{~h}$ before each hyperthermia treatment. The mice were anesthetized with pentobarbital $(\sim 50 \mathrm{mg} / \mathrm{kg})$ before administering hyperthermia. Whole body hyperthermia was performed in a well-ventilated, thermally controlled box heated using infrared rays (Blast Co., Ltd., Tokyo, Japan) in a similar manner as described previously $(19,21)$. The rectal temperature was monitored and maintained at $40-42^{\circ} \mathrm{C}$ and heat-shock was carried out for $1 \mathrm{~h}$. Tumor volume was measured once every week and estimated using the formula for an ellipsoid (length $\mathrm{x}$ width $\mathrm{x}$ height $\mathrm{x}$ 0.55). The tumor volume at 4 weeks of treatment was used as the basis for the calculation of relative tumor volume. Values are the means \pm SE. Significance of the difference between groups were assessed with Student's t-test.

\section{Results}

Co-treatment with IFN- $\gamma$ and hyperthermia suppresses tumor growth in vivo. We first investigated whether IFN- $\gamma$ can enhance the anti-tumor effect of hyperthermia in vivo.
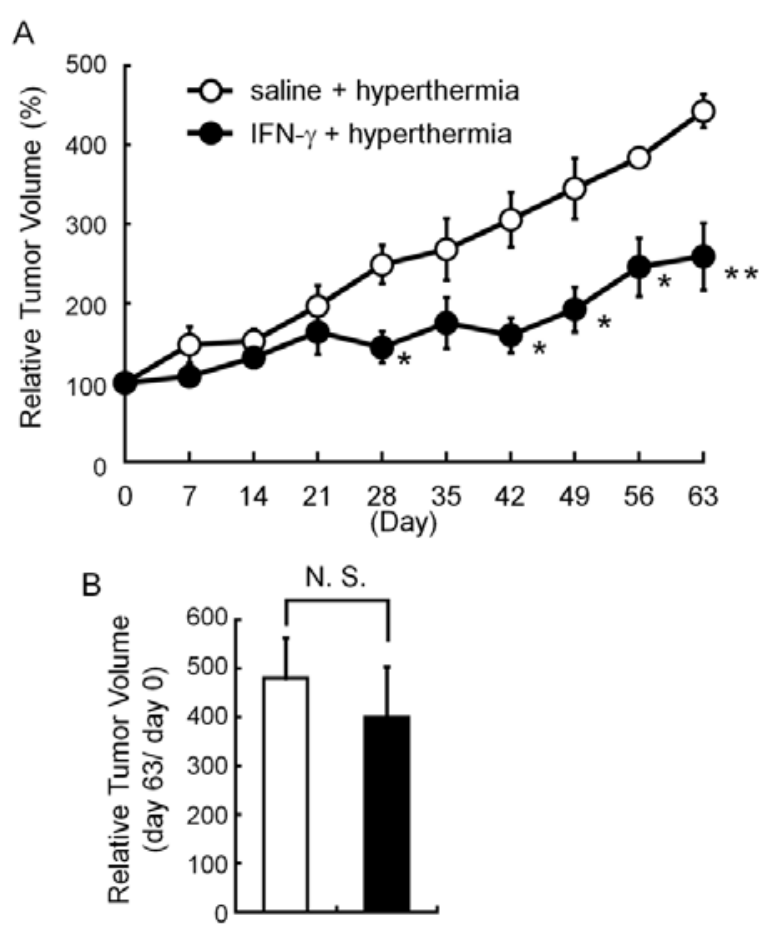

Figure 1. IFN- $\gamma$ and hyperthermia treatment suppressed tumor growth in vivo. (A) A549 tumor-bearing nude mice were subjected once a week to whole body hyperthermia treatment with IFN- $\gamma$ or saline injection. Tumor volume was measured once a week for 9 weeks (63 days) and is expressed as relative tumor volume (\%) (see Materials and methods). The values are presented as mean $\pm \mathrm{SE}$ ( $\mathrm{n}=4$ per group). ${ }^{*} \mathrm{P}<0.05,{ }^{* *} \mathrm{P}<0.01$, assessed by Student's t-test. (B) Relative tumor volume in saline- or IFN- $\gamma$-treated mice without hyperthermia at 63 days after start of treatment. The data shown are mean \pm SE (saline, $n=8 ;$ IFN- $\gamma, n=5$ ). N.S., not significant.

We treated A549 tumor-bearing mice with saline or IFN- $\gamma$ and whole body hyperthermia once a week. Tumor growth difference between saline + hyperthermia (control) and IFN- $\gamma$ + hyperthermia groups was observed after one month of treatment. Mice treated with IFN $-\gamma+$ hyperthermia had significant growth inhibition in tumor volume compared with hyperthermia alone (Fig. 1A). Alternatively, the treatment with IFN- $\gamma$ without hyperthermia did not induce a significant reduction of tumor volume (Fig. 1B). These results indicate that whole body hyperthermia and IFN- $\gamma$ treatment synergistically suppressed tumor growth in mice.

IFN- $\gamma$ suppresses Hsp27 and Hsp72 expression in cancer cell lines. To gain mechanistic insight into how IFN- $\gamma$ potentiates the anti-tumor effect of hyperthermia, we first determined whether IFN- $\gamma$ affects the basal levels of Hsp27 and Hsp72, which are molecules that protect cells from heat stress and promote cell survival. We incubated A549 cells with IFN- $\gamma$ and investigated the protein expression of Hsp27 and Hsp72. We observed that IFN- $\gamma$ but not IFN- $\alpha$ or IFN- $\beta$ downregulated the basal expression of Hsp27 and slightly that of Hsp72 (Fig. 2A) within 48-72 h of treatment (Fig. 2B). We also checked the effect of IFN- $\gamma$ treatment on Hsp27 and Hsp72 in other cell lines. IFN- $\gamma$ slightly reduced Hsp72 expression and markedly reduced Hsp27 expression in HSC-2 and HeLa cells (Fig. 2C and D, respectively). On the other hand, IFN- $\gamma$ did not decrease the level of Hsps in normal 
A

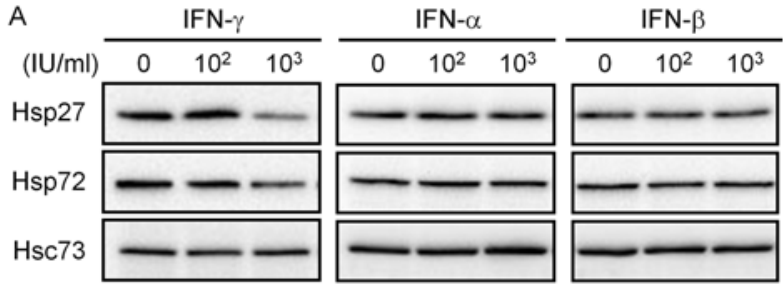

B

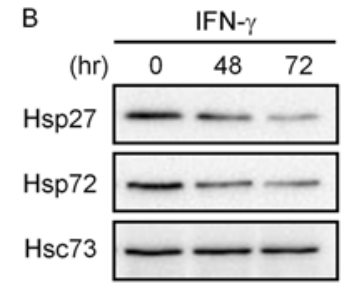

C
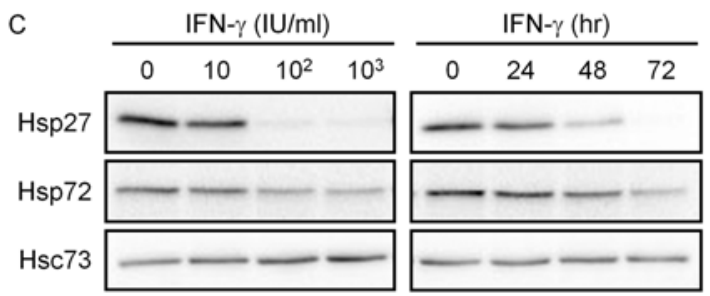

E

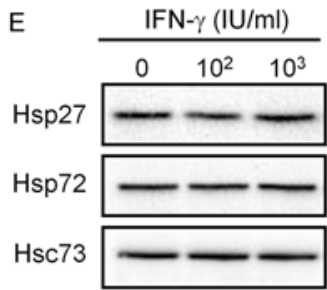

D

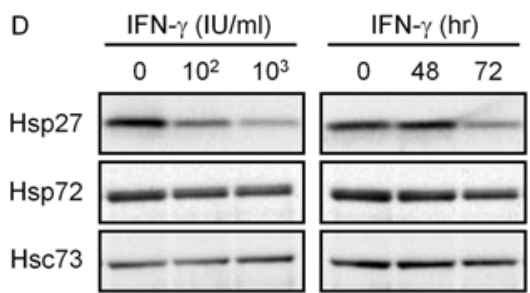

Figure 2. The effects of IFNs on Hsp27 and Hsp72 expression in some cell lines. (A) A549 cells were untreated or treated with IFN- $\alpha,-\beta,-\gamma(100$, $1000 \mathrm{IU} / \mathrm{ml}$ ) for $72 \mathrm{~h}$, or (B) with IFN- $\gamma$ (1000 IU/ml) for 48 or $72 \mathrm{~h}$. (C) HSC-2, (D) HeLa and (E) 16HBE14o- cells were untreated or treated with IFN- $\gamma$ at the indicated concentrations for $72 \mathrm{~h}$ (left panel) or treated with IFN- $\gamma(\mathrm{C}, 100 \mathrm{IU} / \mathrm{ml}$; D and E, $1000 \mathrm{IU} / \mathrm{ml}$ ) at the indicated times (right panel). Whole cell lysates were isolated and subjected to Western blotting with anti-Hsp27, -Hsp72 and -Hsc73 antibodies. Hsc73 was used as internal control.

bronchial epithelial cell line, 16HBE14o- (Fig. 2E). These data suggest that the basal Hsp27 and Hsp72 expression levels are reduced by IFN- $\gamma$ treatment in several types of carcinoma cell lines, but not in normal cells and are consistent with previous reports showing that IFN- $\gamma$ down-regulates the expression of Hsp27 and Hsp72 $(17,18)$.

IFN- $\gamma$ suppresses the expression of Hsps and enhances the cell death induced by heat shock in tumor cells. We next performed Western blotting of lysates from A549, HSC-2 and $16 \mathrm{HBE} 14 \mathrm{o}-$ cells, subjected to heat shock at $42^{\circ} \mathrm{C}$ for $2 \mathrm{~h}$ and untreated or pre-treated with IFN- $\gamma$ at concentrations which were observed to suppress Hsp expression in cancer cell lines, A549 and HSC-2, as shown above (Fig. 2A and C, respectively). As expected, heat shock increased both Hsp27 and Hsp72 expressions in these cell lines (Fig. 3). Interestingly, in A549 and HSC-2 cells, pre-treatment with IFN- $\gamma$ interfered with the induction of Hsp27 and Hsp72 expression after heat shock (Fig. 3A and B). But in normal bronchial epithelial cells, 16HBE140-, pre-treatment with IFN- $\gamma$ had no effect on the induction of Hsps expression after heat shock (Fig. 3C). Thus, pre-treatment with IFN- $\gamma$ negatively controlled the Hsp27 and Hsp72 expressions induced by heat shock in tumor cells but not in normal cells.

We next determined whether pre-treatment with IFN- $\gamma$ would synergize the effect of heat shock on cell death in tumor cells. Cell death was estimated from $\mathrm{LDH}$ release (\%). Heat shock treatment alone at $44^{\circ} \mathrm{C}$ or $42^{\circ} \mathrm{C}$ for $1 \mathrm{~h}$ effected cell killing to some extent, but pre-treatment with IFN- $\gamma$ dramatically enhanced cell death induced by heat shock in A549 and HSC-2 cells (Fig. 3D and E). However, in $16 \mathrm{HBE} 140-$ cells, IFN- $\gamma$ did not enhance heat shockinduced cell death (Fig. 3F). Taken together, IFN- $\gamma$ potentiated the effect of cell death induced by heat shock on tumor cells by suppressing basal and inducible expressions of Hsp27, and partly, Hsp72 in vitro.

IFN- $\gamma$ enhances the cisplatin-induced cell death in tumor cells. It was previously shown that Hsp27 is up-regulated in cisplatin-resistant ovarian tumor cell line, and that cisplatin, a chemotherapeutic agent for treatment of various cancers, induced the expression of Hsp27 (22). We then investigated whether pre-treatment with IFN- $\gamma$ could inhibit the cisplatininduced expression of Hsps by performing Western blotting of lysates from cells untreated or pre-treated with IFN- $\gamma$ and treated with cisplatin. Hsp27 and Hsp72 expressions were upregulated by cisplatin in tumor cells, A549 and HSC-2, but pre-treatment with IFN- $\gamma$ inhibited the basal and cisplatininduced Hsps expression (Fig. 4A and B). In contrast, in 16HBE14o- cells, cisplatin did not induce the expression of Hsps and pre-treatment with IFN- $\gamma$ had no effect on the level of these proteins (Fig. 4C). Thus, the results indicated that pre-treatment with IFN- $\gamma$ also inhibits cisplatin-induced Hsp27 and Hsp72 expression in these tumor cell lines.

Because IFN- $\gamma$ was able to inhibit cisplatin-induced Hsps expression (Fig. 4A and B), we next examined whether IFN- $\gamma$ can sensitize the tumor cells to cisplatin treatment. Cisplatin-induced cell death was estimated from LDH release $(\%)$. Treatment with cisplatin alone for $24 \mathrm{~h}$ slightly increased cell killing in a dose-dependent manner. However, pre-treatment with IFN- $\gamma$ significantly enhanced the dosedependent cisplatin-induced cell death in A549 and HSC-2 


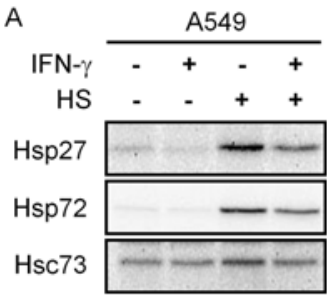

D $\quad$ A549

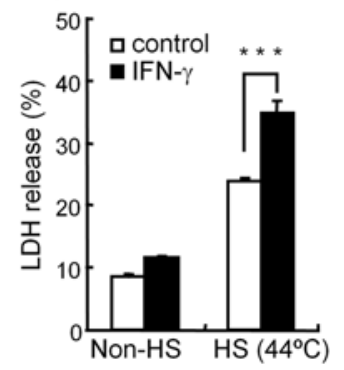

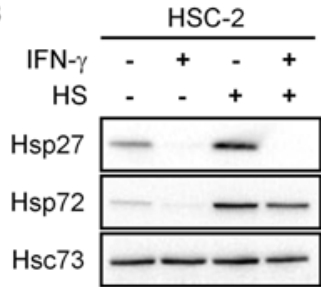

E HSC-2

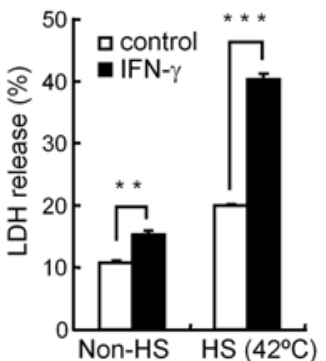

C

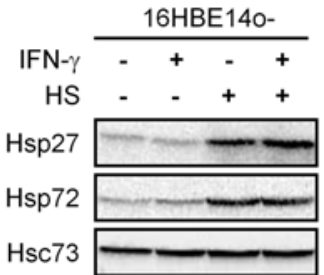

F

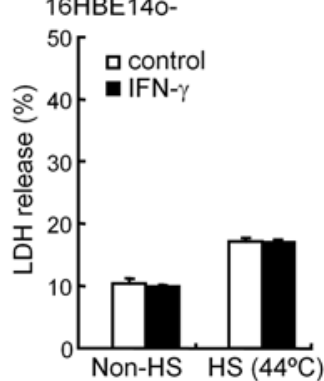

Figure 3. Pre-treatment with IFN- $\gamma$ suppressed the heat shock-induced expression of Hsps and enhanced the cell death in carcinoma cell lines but not in normal cells. Cells were untreated or pre-treated with $1000 \mathrm{IU} / \mathrm{ml} \mathrm{IFN}-\gamma$ in (A) A549 and (C) 16HBE14o- or with $100 \mathrm{IU} / \mathrm{ml} \mathrm{IFN}-\gamma$ in (B) HSC-2 for $62 \mathrm{~h}$. Then cells were subjected to heat shock (HS) for $2 \mathrm{~h}$ at $42^{\circ} \mathrm{C}$ and were re-incubated at $37^{\circ} \mathrm{C}$. Protein lysates were isolated $8 \mathrm{~h}$ after heat shock treatment and analyzed by Western blotting with the indicated antibodies. Hsc73 was used as internal control. (D) A549, (E) HSC-2 and (F) 16HBE14o- cells were untreated or pre-treated with IFN- $\gamma$ as above for $72 \mathrm{~h}$. Heat shock was performed for $1 \mathrm{~h}$ at $44^{\circ} \mathrm{C}(\mathrm{D}$ and $\mathrm{F})$ or $42^{\circ} \mathrm{C}(\mathrm{E})$. Culture media and cells were recovered $24 \mathrm{~h}$ after heat shock treatment. The percentage of cell death was determined by LDH assay. Three independent experiments were each performed in triplicate, and the values are expressed as mean $\pm \mathrm{SE} .{ }^{* *} \mathrm{P}<0.01,{ }^{* * *} \mathrm{P}<0.001$, assessed by one-way ANOVA.

A

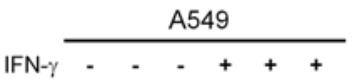

$\operatorname{CDDP}(\mu \mathrm{g} / \mathrm{ml}) \quad 0 \quad 5 \quad 10 \quad 0 \quad 5 \quad 10$
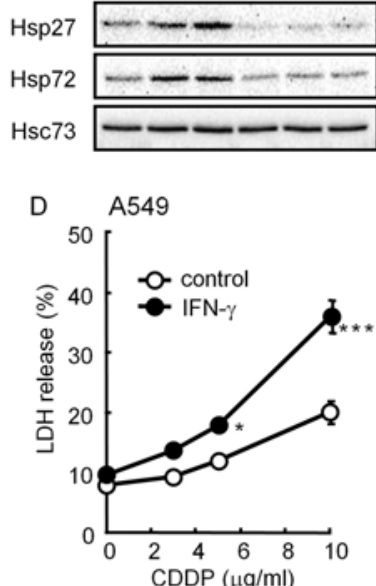

B

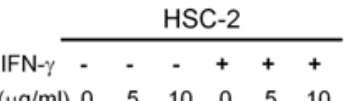

$\operatorname{CDDP}(\mu \mathrm{g} / \mathrm{ml}) \quad 0 \quad 5 \quad 10 \quad 0 \quad 5 \quad 10$
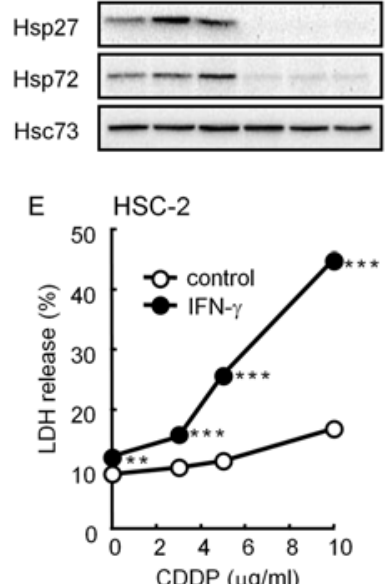

C

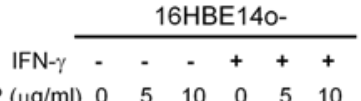

$\operatorname{CDDP}(\mu \mathrm{g} / \mathrm{ml}) \quad 0 \quad 5 \quad 10 \quad 0 \quad 5 \quad 10$

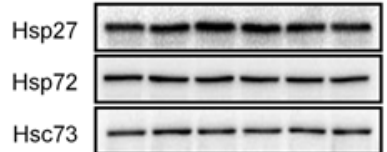

$\mathrm{F}$

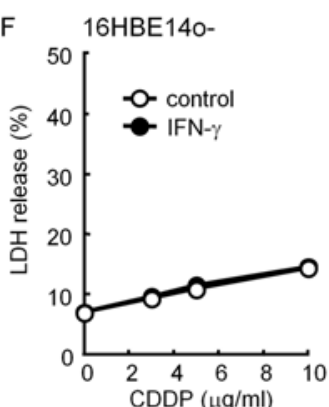

Figure 4. Pre-treatment with IFN- $\gamma$ suppressed the cisplatin-induced expression of Hsps and enhanced the cell death in carcinoma cell lines but not in normal cells. Cells were untreated or pre-treated with $1000 \mathrm{IU} / \mathrm{ml} \mathrm{IFN- \gamma}$ in (A) A549 and (C) 16HBE14o- or with $100 \mathrm{IU} / \mathrm{ml} \mathrm{IFN}-\gamma$ in (B) HSC-2 for $64 \mathrm{~h}$. Cisplatin ( 5 and $10 \mu \mathrm{g} / \mathrm{ml}$ ) was added and cells were incubated for an additional $8 \mathrm{~h}$. After these treatments, protein lysates were recovered and analyzed by Western blotting with anti-Hsp27, -Hsp72 and -Hsc73 (control) antibodies. (D) A549, (E) HSC-2 and (F) 16HBE14o- cells were pre-treated with IFN- $\gamma$ as above for $72 \mathrm{~h}$. Cisplatin $(3,5$ and $10 \mu \mathrm{g} / \mathrm{ml})$ was added and cells were incubated for an additional $24 \mathrm{~h}$. Culture medium and cells were recovered and the percentage of cell death was determined by LDH assay. Three independent experiments were each performed in triplicate and the values are expressed as mean \pm SE. ${ }^{*} \mathrm{P}<0.05,{ }^{* *} \mathrm{P}<0.01$ and ${ }^{* * *} \mathrm{P}<0.001$ assessed by one-way ANOVA.

cells (Fig. 4D and E). But in 16HBE14o- cells, IFN- $\gamma$ treatment did not have any effect on the LDH release (Fig. 4F). Taken together, IFN- $\gamma$ potentiated the effect of cisplatin on tumor cells by suppressing Hsp27 and Hsp72 expression.

IFN- $\gamma$ affects the basal transcription of Hsp27 in A549 cells. Because the suppressive effect of IFN- $\gamma$ was more pronounced in Hsp27 than Hsp72 especially under heat shock condition, we focused on investigating the molecular mechanism of IFN- $\gamma$-induced suppression of Hsp27. We asked whether the down-regulation of Hsp27 upon IFN- $\gamma$ treatment occurred at the transcriptional level. We performed quantitative realtime PCR on A549 cells treated with IFN- $\gamma$. As shown in Fig. 5, the Hsp27 mRNA level was decreased, suggesting 
A
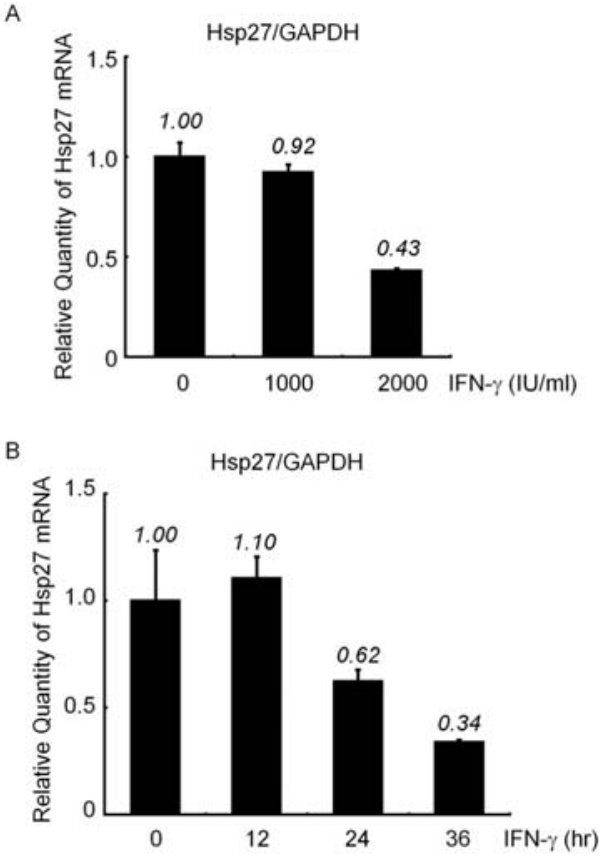

Figure 5. IFN- $\gamma$ down-regulated the mRNA expression of Hsp27 in A549 cells. The mRNA expression of Hsp27 was measured by quantitative realtime RT-PCR in A549 cells, which were treated with IFN- $\gamma$ (A) at the indicated concentrations for $72 \mathrm{~h}$ or (B) at $2000 \mathrm{IU} / \mathrm{ml}$ for the indicated times. Hsp27 mRNA levels were normalized to the level of GAPDH (internal control). The values are expressed as mean $\pm \mathrm{SE}(\mathrm{A}, \mathrm{n}=2 ; \mathrm{B}, \mathrm{n}=3)$.

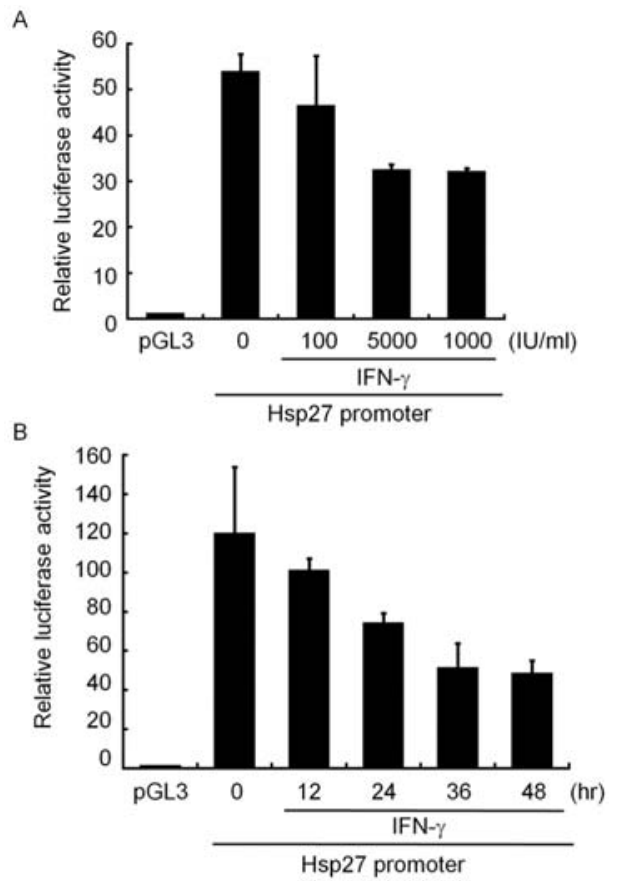

Figure 6. IFN- $\gamma$ decreased the basal transcription of Hsp27 promoter in A549 cells. A549 cells were transfected with Hsp27 promoter construct $(-1090 /+38)$ and treated with IFN- $\gamma(\mathrm{A})$ at the indicated concentrations for $48 \mathrm{~h}$ or (B) at $1000 \mathrm{IU} / \mathrm{ml}$ for the indicated times. Luciferase activity of lysates was determined $48 \mathrm{~h}$ after transfection, and is expressed as fold activation over the empty vector. Values are expressed as mean \pm SE. $(n=3)$.

that IFN- $\gamma$ regulates the basal transcription of Hsp27. Furthermore, we measured the promoter activity of Hsp27 using a
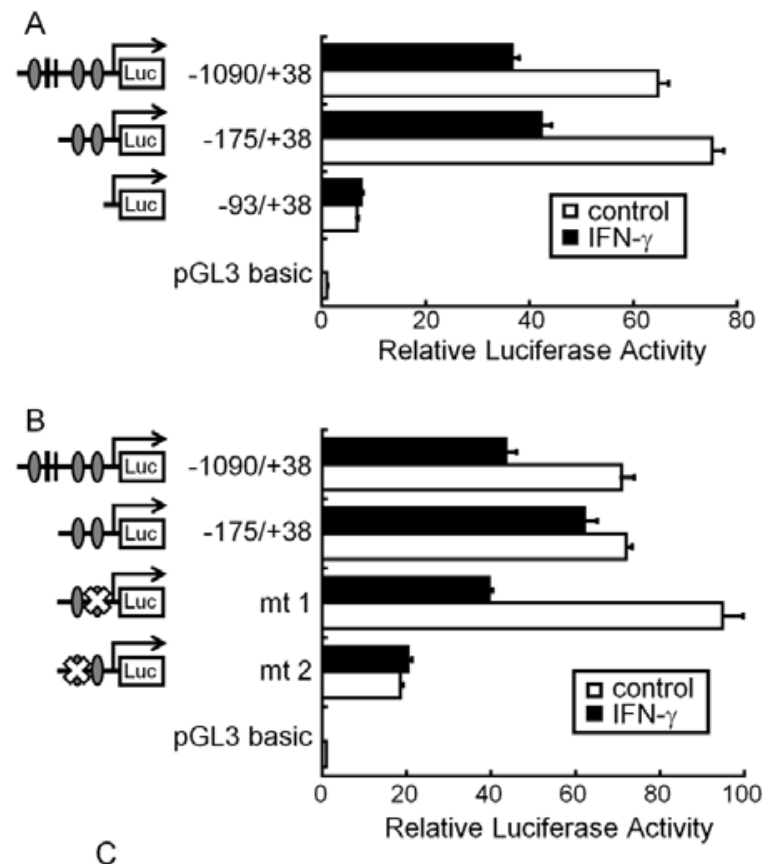

C

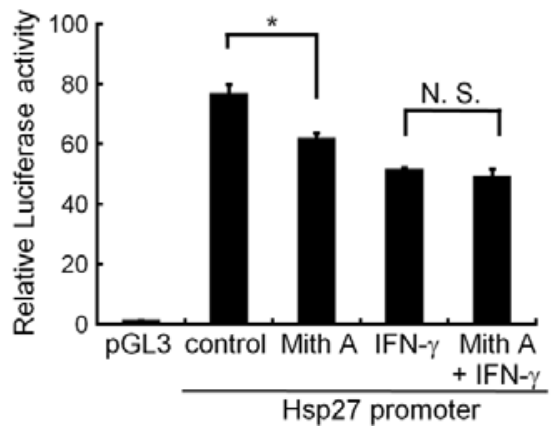

Figure 7. Sp1 is important for the IFN- $\gamma$-induced suppression of Hsp27 promoter activity. (A and B) A549 cells were transfected with the indicated Hsp27 promoter constructs and untreated or treated with IFN- $\gamma(1000 \mathrm{IU} / \mathrm{ml})$ for $48 \mathrm{~h}$. The constructs are represented at the left, with gray circles as the Sp1 binding sites. (C) A549 cells were transfected with Hsp27 promoter construct $(-1090 /+38)$. Twelve hours before assay, cells were treated with $500 \mathrm{nM}$ mithramycin A (Mith A) alone or in combination with $1000 \mathrm{IU} / \mathrm{ml}$ IFN- $\gamma$. Luciferase activity of lysates was determined $48 \mathrm{~h}$ after transfection, and is expressed as fold activation over the empty vector. Values are mean $\pm \mathrm{SE}(\mathrm{n}=3) .{ }^{*} \mathrm{P}<0.05$, assessed by one-way ANOVA. N.S., not significant.

luciferase reporter construct of 1.1-kb Hsp27 promoter. Hsp27 promoter activity was dose- and time-dependently suppressed by IFN- $\gamma$ (Fig. 6A and B). These data indicated that IFN- $\gamma$ treatment affects the transcriptional activity of Hsp27.

Spl is important for the suppression of Hsp 27 promoter activity by IFN- $\gamma$ in A549 cells. To identify the region within the 1.1-kb Hsp27 promoter that is important for its response to IFN- $\gamma$, we generated deletion promoter constructs, and checked the luciferase activity of these constructs in A549 cells untreated or treated with IFN- $\gamma$. The constructs that contain $2 \mathrm{Sp} 1$ binding sites (represented as gray circles) at the proximal region, which were previously reported to be important for basal Hsp27 promoter activity (20), were responsive to IFN- $\gamma$ treatment (Fig. 7A). We created point mutations at these $\mathrm{Sp} 1$ sites to determine which site is more likely responsible for the promoter's response to IFN- $\gamma$. 
When the Sp1 site nearest to the transcription start site was mutated (Fig. 7B; mt1), the promoter was still sensitive to IFN- $\gamma$ treatment. On the other hand, when the second Sp1 site was point mutated ( $\mathrm{mt} 2$ ), the basal activity as well as the promoter's response to IFN- $\gamma$ was abolished (Fig. 7B). The presence of the first $\mathrm{Sp} 1$ site that is unmutated could not further down-regulate the promoter activity in the presence of IFN- $\gamma$, suggesting that the second $\mathrm{Sp} 1$ site was specifically necessary for promoter activation as well as for the response to IFN- $\gamma$.

In addition, we determined whether the inhibitory effect of IFN- $\gamma$ on the Hsp27 promoter activity could still be detected after treatment of cells with mithramycin A, an inhibitor of Sp1 binding. In the presence of mitramycin A, the Hsp27 promoter was less responsive to the effect of IFN- $\gamma$ (Fig. 7C). Taken together, these data suggest that the regulatory effect of IFN- $\gamma$ on Hsp27 transcriptional activity may be mediated through the $\mathrm{Sp} 1$ binding site in the Hsp27 promoter region.

\section{Discussion}

Although previous reports have shown the anti-proliferative effect of hyperthermia together with combination interferon (IFN- $\gamma$ and $-\alpha$, or $-\beta)$ treatment in vitro $(15,16)$, our present report is the first to demonstrate the in vivo tumor-growth suppressive effect of hyperthermia combined with interferon- $\gamma$. Furthermore, we showed that IFN- $\gamma$ down-regulated the heat shock-induced expressions of Hsp27 and Hsp72, which was most likely responsible for the synergistic effect of IFN- $\gamma$ on hyperthermia treatment in tumor-killing (23). IFN- $\gamma$, but not IFN- $\alpha$ or IFN- $\beta$, affected both the basal and inducible expressions of Hsps in carcinoma cell lines, A549, HeLa and HSC-2, while those in normal cells (16HBE14o-) were not changed by the treatment (Figs. 2 and 3), demonstrating the specificity of IFN- $\gamma$ 's effect on tumor cells. Consistent with these results, we observed that heat shock- and cisplatininduced cell death of cancer cells, but not normal cells, was enhanced by IFN- $\gamma$ pre-treatment (Figs. 3 and 4). The reason for the differential response of tumor cells and normal cells to IFN- $\gamma$, however, is yet to be clarified. Our results extended the findings of Yonekura et al, in which they showed that IFN- $\gamma$ suppresses Hsp27 and induces cell death specifically in oral squamous carcinoma cells (18). But unlike the Yonekura findings, we observed that IFN- $\gamma$ was effective in other carcinoma cells as well, such as A549 and HeLa, albeit at a lower magnitude than in HSC-2. This difference, especially in HeLa cells, may be attributed to the differences in experimental methods such as IFN- $\gamma$ treatment time. We observed that Hsp27 expression was down-regulated after treatment with $1000 \mathrm{IU} / \mathrm{ml}$ for $72 \mathrm{~h}$ (Fig. 2D), whereas Yonekura and co-authors treated the HeLa cells with 1000 $\mathrm{IU} / \mathrm{ml}$ for $48 \mathrm{~h}$ (18). Taken together, the combination therapy of hyperthermia and IFN- $\gamma$ likely affects not only oral squamous cell carcinoma but also several types of cancer tissues that highly express Hsps (24).

In addition, we investigated the mechanisms of IFN- $\gamma$ induced Hsp27 down-regulation. When cells are heated, heat shock factor-1 (HSF-1), the main transcription factor for heat-induced Hsp expression, is phosphorylated and translocates to the nucleus (25). We checked the effect of IFN- $\gamma$ on HSF-1 activation induced by heat-shock, but we found that IFN- $\gamma$ did not affect heat-induced HSF-1 phosphorylation and nuclear translocation (data not shown). However, we observed that the promoter of Hsp27 itself is responsive to IFN- $\gamma$ (Figs. 6 and 7), suggesting that IFN- $\gamma$ regulates the transcriptional activity of Hsp27. By deletion analysis, we found that the proximal region of $\mathrm{Hsp} 27$ promoter contains elements necessary for its response to IFN- $\gamma$. It was previously shown that $\mathrm{Sp} 1$ regulates the basal promoter activity of Hsp27, a finding that we were able to reproduce here (20). But the previous work did not specify which of the $2 \mathrm{Sp} 1$ sites in the proximal promoter was more important for Hsp27 basal activity. In contrast, we were able to prove, by point mutation, that the second Sp1 site was specifically necessary and sufficient not only for Hsp27 basal activity but also for its response to IFN- $\gamma$ (Fig. 7B). This particular observation is not without precedent; Hughes et al, demonstrated that Sp1 binding site is important for the IFN- $\gamma$-mediated suppression of lipoprotein lipase gene, and the mutation of an $\mathrm{Sp} 1$ site abolished the promoter activity as well as the effect of IFN- $\gamma$ on the promoter (26). In another study, Amin et al also reported that knockdown of $\mathrm{Sp} 1$ and $\mathrm{Sp} 3$ resulted in the down-regulation of human sodium-hydrogen exchanger (NHE) expression and resistance to the suppressive effect of IFN- $\gamma$ and TNF- $\alpha$ (27). These studies implicate a role of the Sp1 family in mediating the inhibitory effect of IFN- $\gamma$ on various target genes.

The reason why IFN- $\gamma$, but not the type I IFNs (IFN- $\alpha /-\beta)$, can inhibit Hsp27 remains unclear. IFN- $\gamma$-specific signaling pathway, such as PKA activation, which affects phosphorylation status and binding activity of Sp1 (28), may be involved in this particular mechanistic regulation $(10,27,29)$. Whether IFN- $\gamma$ blocks the binding of Sp1 on the Hsp27 promoter still needs to be assessed, although this is likely, in view of the findings presented previously $(26,27)$.

The combinatorial effect of hyperthermia or cisplatin and IFN- $\gamma$ on tumor cell death may also be partly through the down-regulation of Hsp72 because IFN- $\gamma$ treatment slightly suppressed Hsp72 expression (Figs. 2-4). Although it is not known whether, and how, IFN- $\gamma$ affects Hsp72 transcriptional activity, it is possible that it might also be through $\mathrm{Sp} 1$ because the Hsp70 gene promoter could be activated by Sp1 (30). On the whole, our results presented here, that IFN- $\gamma$ suppresses inducible Hsps expression during hyperthermia or cisplatin treatment, and enhance tumor cell killing suggest that IFN- $\gamma$ could be a useful potentiator of hyperthermia and chemotherapeutic agents for cancer therapy.

\section{Acknowledgements}

The HSC-2 cell line was a gift from Dr A. Uehara of Tohoku University, Japan. The IFN- $\alpha$ was a gift from Yamanouchi Pharmaceutical (Tokyo, Japan). The IFN- $\beta$ was provided by TORAY Industries (Chiba, Japan). The cisplatin reagent was provided by Nippon Kayaku (Tokyo, Japan). The IR box for whole body hyperthermia was kindly provided by Blast Co., Ltd. (Tokyo, Japan). This work was supported by the Sasagawa Scientific Research Grant from the Japan Science Society, grants from the Ministry of Education, Science, Culture and Sport (MEXT) of Japan and from the Global 
COE Program (Cell Fate Regulation Research and Education Unit), MEXT, Japan.

\section{References}

1. Hildebrandt B, Wust $\mathrm{P}$, Ahlers $\mathrm{O}$, et al: The cellular and molecular basis of hyperthermia. Crit Rev Oncol Hematol 43: 33-56, 2002.

2. Van der Zee J: Heating the patient: a promising approach? Ann Oncol 13: 1173-1184, 2002.

3. Repasky EA, Tims E, Pritchard M and Burd R: Characterization of mild whole-body hyperthermia protocols using human breast, ovarian, and colon tumors grown in severe combined immunodeficient mice. Infect Dis Obstet Gynecol 7: 91-97, 1999.

4. Sarto C, Binz PA and Mocarelli P: Heat shock proteins in human cancer. Electrophoresis 21: 1218-1226, 2000.

5. Jaattela M: Escaping cell death: survival proteins in cancer. Exp Cell Res 248: 30-43, 1999

6. Lavoie JN, Gingras-Breton G, Tanguay RM and Landry J: Induction of Chinese hamster HSP27 gene expression in mouse cells confers resistance to heat shock. HSP27 stabilization of the microfilament organization. J Biol Chem 268: 3420-3429, 1993.

7. Concannon CG, Gorman AM and Samali A: On the role of Hsp27 in regulating apoptosis. Apoptosis 8: 61-70, 2003.

8. Kiang JG and Tsokos GC: Heat shock protein $70 \mathrm{kDa}$ : molecular biology, biochemistry and physiology. Pharmacol Ther 80 : 183-201, 1998

9. Didelot C, Lanneau D, Brunet M, et al: Anti-cancer therapeutic approaches based on intracellular and extracellular heat shock proteins. Curr Med Chem 14: 2839-2847, 2007.

10. Schroder K, Hertzog PJ, Ravasi T and Hume DA: Interferongamma: an overview of signals, mechanisms and functions. J Leukoc Biol 75: 163-189, 2004.

11. Chawla-Sarkar M, Lindner DJ, Liu YF, et al: Apoptosis and interferons: role of interferon-stimulated genes as mediators of apoptosis. Apoptosis 8: 237-249, 2003

12. Barton C, Davies D, Balkwill F and Burke F: Involvement of both intrinsic and extrinsic pathways in IFN-gamma-induced apoptosis that are enhanced with cisplatin. Eur J Cancer 41: 1474-1486, 2005

13. Vickers SM, Jhala NC, Ahn EY, McDonald JM, Pan G and Bland KI: Tamoxifen (TMX)/Fas induced growth inhibition of human cholangiocarcinoma (HCC) by gamma interferon (IFN-gamma). Ann Surg 235: 872-878, 2002.

14. Wadler S and Schwartz EL: Antineoplastic activity of the combination of interferon and cytotoxic agents against experimental and human malignancies: a review. Cancer Res 50: 3473-3486, 1990.

15. Fleischmann WR Jr, Fleischmann CM and Gindhart TD: Effect of hyperthermia on the antiproliferative activities of murine alpha-, beta- and gamma-interferon: differential enhancement of murine gamma-interferon. Cancer Res 46: 8-13, 1986.
16. Fleischmann WR Jr, Fleischmann CM and Gindhart TD: Effect of hyperthermia on combination interferon treatment: enhancement of the antiproliferative activity against murine B-16 melanoma. Cancer Res 46: 1722-1726, 1986.

17. Saile B, Eisenbach C, Dudas J, El-Armouche H and Ramadori G: Interferon-gamma acts proapoptotic on hepatic stellate cells (HSC) and abrogates the antiapoptotic effect of interferon-alpha by an HSP70-dependant pathway. Eur J Cell Biol 83: 469-476, 2004.

18. Yonekura N, Yokota S, Yonekura K, et al: Interferon-gamma down-regulates Hsp27 expression and suppresses the negative regulation of cell death in oral squamous cell carcinoma lines. Cell Death Differ 10: 313-322, 2003.

19. Shimohara S, Murakami T, Morikawa M, et al: Vitamins K1 and $\mathrm{K} 2$ potentiate hyperthermia by down-regulating Hsp72 expression in vitro and in vivo. Int J Oncol 27: 1527-1533, 2005.

20. Oesterreich S, Hickey E, Weber LA and Fuqua SA: Basal regulatory promoter elements of the hsp 27 gene in human breast cancer cells. Biochem Biophys Res Commun 222: 155-163, 1996.

21. Koga T, Harada H, Shi TS, et al: Hyperthermia suppresses the cytotoxicity of NK cells via down-regulation of perforin/ granzyme B expression. Biochem Biophys Res Commun 337: 1319-1323, 2005.

22. Yamamoto K, Okamoto A, Isonishi S, Ochiai K and Ohtake Y: Heat shock protein 27 was up-regulated in cisplatin resistant human ovarian tumor cell line and associated with the cisplatin resistance. Cancer Lett 168: 173-181, 2001.

23. Garrido C, Schmitt E, Cande C, Vahsen N, Parcellier A and Kroemer G: HSP27 and HSP70: potentially oncogenic apoptosis inhibitors. Cell Cycle 2: 579-584, 2003.

24. Lebret T, Watson RW, Molinie V, et al: Heat shock proteins HSP27, HSP60, HSP70 and HSP90: expression in bladder carcinoma. Cancer 98: 970-977, 2003.

25. Morimoto RI: Regulation of the heat shock transcriptional response: cross talk between a family of heat shock factors, molecular chaperones and negative regulators. Genes Dev 12: 3788-3796, 1998.

26. Hughes TR, Tengku-Muhammad TS, Irvine SA and Ramji DP A novel role of Sp1 and Sp3 in the interferon-gamma-mediated suppression of macrophage lipoprotein lipase gene transcription. J Biol Chem 277: 11097-11106, 2002.

27. Amin MR, Malakooti J, Sandoval R, Dudeja PK and Ramaswamy K: IFN-gamma and TNF-alpha regulate human NHE3 gene expression by modulating the Sp family transcription factors in human intestinal epithelial cell line C2BBe1. Am J Physiol Cell Physiol 291: C887-C896, 2006.

28. Rohlff C, Ahmad S, Borellini F, Lei J and Glazer RI: Modulation of transcription factor Sp1 by cAMP-dependent protein kinase. J Biol Chem 272: 21137-21141, 1997.

29. Van Boxel-Dezaire AH and Stark GR: Cell type-specific signaling in response to interferon-gamma. Curr Top Microbiol Immunol 316: 119-154, 2007.

30. Morgan WD: Transcription factor $\mathrm{Sp} 1$ binds to and activates a human hsp70 gene promoter. Mol Cell Biol 9: 4099-4104, 1989. 